\title{
Performance Analysis of Synchronous Generator: A Case Study in Steam Power Plant at PT POMI Paiton Unit 7 Probolinggo, East Java, Indonesia
}

\author{
Ramadoni Syahputra $^{* 1}$, Andi Wahyu Nugroho ${ }^{1}$, Anna Nur Nazilah Chamim ${ }^{1}$, Widyasmoro ${ }^{1}$ and \\ Teguh Iman Prasetyo ${ }^{2}$ \\ ${ }^{1}$ Department of Electrical Engineering, Universitas Muhammadiyah Yogyakarta \\ Jl. Lingkar Selatan, Tamantirto, Kasihan, Yogyakarta, Indonesia \\ ${ }^{2}$ Production on the Job Trainer and Competence Assessor, Petroleum Development Oman \\ Muscat, Sultanate of Oman \\ *Corresponding author, e-mail: ramadoni@umy.ac.id
}

\begin{abstract}
This paper presents performance analysis of synchronous generator: a case study in steam power plant PT POMI Paiton unit 7 Probolinggo, East Java, Indonesia. The steam power plant is the most powerful in Indonesia. The dominance of this type of power plant can be seen from statistical data that until the end of 2018 there were $48.43 \%$ of steam power plants out of the total installed capacity of national plants. Generators used in steam power plants are generally of the synchronous generator type, which in its operation always experiences dynamics from time to time as the load changes in electricity. In this study, an analysis of the performance of synchronous generators has been carried out concerning changes in electricity load. Synchronous generator performance analysis includes output voltage, active power, reactive power, power factor, and generator efficiency. The steam power plant in this study is the largest capacity power plant in Indonesia, thus providing an important role in the supply of electric power. Based on the results of the study, it has been shown that although the load dynamics that experience changes are very dynamic, the generator performance still has good performance.
\end{abstract}

Keywords: Synchronous Generator, Steam Power Plant, Voltage, Efficiency

\section{Introduction}

Energy supply derived from fossil or biomass energy is generally through the process of combustion of carbon compounds which will produce exhaust emissions, especially $\mathrm{CO}_{2}$ gas. Primary energy needs in the world today are still dominated by fossil energy by more than $80 \%$ in 2013 and projected to fall to $75 \%$ in 2030 . Coal supports $30 \%$ of $80 \%$ of fossil energy in 2013 [1].

Globally, the world's power generation sector accounted for $40 \%$ of $\mathrm{CO}_{2}$ gas emissions, followed by the transportation and industrial sectors in 2014 . In the European Union, $\mathrm{CO}_{2}$ emissions fell by more than $200 \mathrm{Mt}$ (more than $6 \%$ ) due to the need for fossil fuels such as natural gas down $12 \%$ and nonhydro renewable fuels rose $12 \% . \mathrm{CO}_{2}$ emissions in Japan have decreased by $3 \%$ in 2014 compared to 2013 due to decreased oil demand and increased LNG imports as a result of the shutdown of nuclear power plants. $\mathrm{CO}_{2}$ emissions in the power generation sector in the US dropped $11 \%$ due to the increase in non-hydro renewable energy and also the increase in electricity demand is not too large, but there was an increase in the use of natural gas in the industrial and building sectors [1].

The status of primary energy for electricity generation in Indonesia is still dominated by fossil fuels, namely oil, gas, and coal. In 2024 it is 
projected that the composition of electricity production per primary energy type in Indonesia will be $63.7 \%$ coal, 19.2\% natural gas (including LNG), $9 \%$ geothermal, $6.6 \%$ hydropower, $1.5 \%$ oil and other fuel. At present, the fossil primary energy for power generation is $54 \%$ coal, followed by $21 \%$ gas and $2 \%$ oil (RUPTL 2015-2024).

Based on the data above, it has been reflected that most of the power plants in Indonesia are steam power plants. This fact makes important information that steam power plants are very popular in Indonesia, even in the world. Generally, steam power plants use synchronous generators as a tool to generate electricity. Generators are electric power generation machines, generators are obtained by receiving mechanical power and converted into electric power, mechanical power for generators for example for use in workshops or schools, generally used diesel engines, diesel engines and generators are usually installed into one unit. This unit is commonly called a generator set. Generator sets generally produce alternating current electricity of one or three phases. In the past, generators with the engine were generally connected indirectly, but using intermediate belts or tires. Alternating current generators, sometimes called synchronous generators or alternators, provide an important connection in the long process of changing the energy in the form of coal, oil, gas, or uranium into a form that is useful for use in industry and households. Large generators that are used to supply modern national electricity grids are driven by steam turbines or waterwheels. Generators used to supply separate power systems, or smaller systems or to supplement additional peak load power against larger grids are often driven by diesel engines or fuel turbines.

\section{Literature Study}

\section{II.1 Steam Power Plant}

Steam power plant centers are currently the choice of large-scale power conversion from conventional fuels to power to meet the needs of large load demands. This power plant uses conventional fuels, namely coal, oil, or natural gas to generate heat and steam in the boiler [2]. The steam is then used to turn turbines that are coupled directly with synchronous generators. After passing through a steam turbine, the high pressure and high temperature steam coming from the boiler becomes low pressure and low temperature steam. Then this steam enters the condenser and the heat or temperature of the steam is then absorbed by the condenser so that the steam turns into water which is then pumped back into the boiler. The remaining heat discharged by the condenser had reached half of the initial amount of heat that enters.

In generating electricity, a steam power plant requires a synergy between several of its components. The main components in a steam power plant can be seen in Figure 1.

A drum containing water and pressurized steam and high temperatures produces the steam needed by the turbine. The drum also receives fill water received from the condenser. Boiler filling water is pumped from outside into the boiler by using a boiler filling water pump from a pressure of 1 bar to reach a working pressure of $p$ bar inside the boiler. Water that is used to fill the boiler is distillation water that has been free from pollutants contained in water in general such as solid dust, floating substances, salt, dissolved gases, colloidal or colloidal substances. The deep water is then heated using existing conventional fuels so that high pressure and high temperature steam is formed, the steam then flows into the high pressure turbine after passing through the superheater to increase the temperature of the steam to about $500{ }^{\circ} \mathrm{C}-600{ }^{\circ} \mathrm{C}$ thus the steam also dried up and the efficiency of the entire power plant increased [3].

A superheater is a device for heating full steam to further heated steam (superheater steam). Steam which is heated further when used to carry out work by means of expansion in the steam turbine will not quickly condense, thereby reducing the possibility of danger caused by a back stroke (back stroke) due to condensation of steam not in time so that it creates a vacuum in the place it should not be in the expansion area. "The term satiety vapor is vapor that is in a state of balance with the water underneath, meaning that steam has the same pressure and boiling temperature as the pressure and boiling temperature of the water underneath and when cooled will immediately condense into water .

Steam that flows in a high pressure turbine causes the turbine to spin so that it converts heat energy into mechanical energy. The turbine is coupled to a synchronous generator that converts mechanical energy in the turbine to electrical energy. After passing through the turbine, the high pressure and high temperature steam decreases in temperature so that it becomes low pressure and temperature steam. To increase heat efficiency and avoid condensation too early, this steam is then passed back to a superheater, which also consists of rows of heated pipes. Steam that leaves the reheat, 
the result of reheating, is channeled to the medium pressure turbine, thus turning the medium pressure turbine, this turbine is also coupled to the same synchronous generator as the high pressure turbine.
This medium pressure turbine is bigger than a high pressure turbine, because with a decrease in steam pressure, the volume will increase.

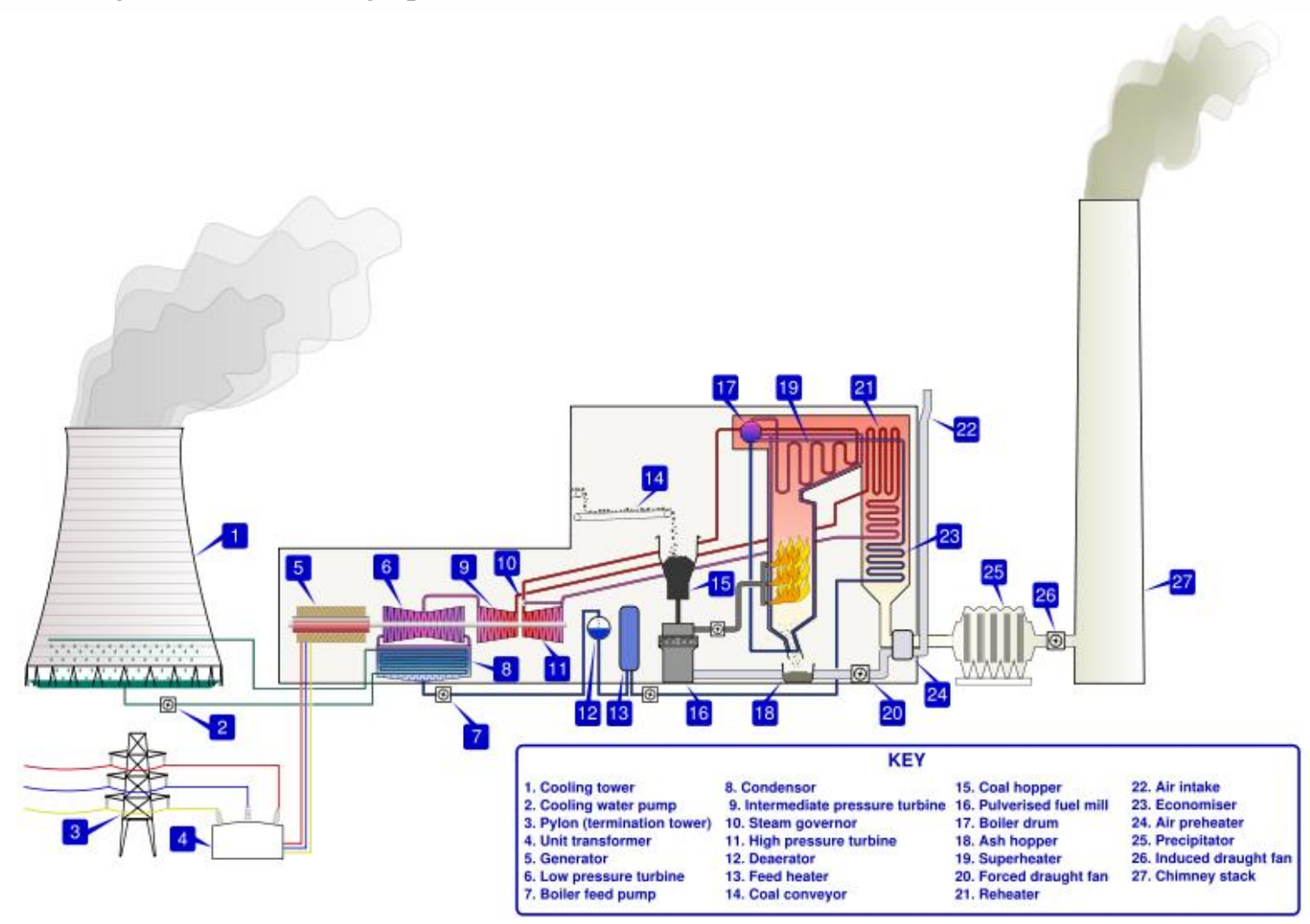

Fig. 1. The main components in a steam power plant

After passing through a medium pressure turbine the steam is then flowed to a low pressure turbine and rotates a low pressure turbine coupled to the same generator as the two previous turbines, this low pressure turbine has an even bigger size, steam that has passed through a low pressure turbine is then flowed into the condenser.

Steam that has passed through a low pressure turbine then enters the condenser and is cooled by cooling water so that condensation occurs which causes the steam to become water. The cooling water usually comes from the nearest sea, river or lake. The warm water leaving the condenser is then pumped into a preheater before returning to the boiler drum. The preheater gets heat from steam taken from high pressure turbines. According to various literature, this thus increases the overall efficiency of steam power plants. The fuel used usually consists of bolts, petroleum, or natural gas.

Before putting into a boiler burner, the coal is ground first. Likewise, fuel oil needs to be heated, before it can be flowed into the boiler burner. A fan is used to regulate the entry of air into the boiler in large quantities as needed for combustion and another fan regulates that all exhaust gases pass through various cleaning devices before being flowed into the chimney and released in the air free, this fan creates forced chimney suction so that there is a considerable difference in density between the air and the flue gas. Chimney is used to drain smoke gas out of the boiler with a certain speed, and is used to overcome the friction that occurs in the flow of smoke gas, starting from the frame of the combustion or combustion, until out of the chimney. In other words, to cause stack chimneys or stack draft, in addition to killing smoke gas as high as possible so that it does not disturb the surrounding environment. The emergence of smoke chimney suction is caused by differences in Specific Gravity, between the specific gravity of the air with the specific gravity of the flue gas. The electric generator is mounted on the same shaft as the three turbines.

\section{II.2 Synchronous Generator}

A generator is a machine that manages mechanical energy into electrical energy. The 
working principle of a generator is a rotor generator that is driven by a turbine that causes electricity [4, 5]. Energy sources for turbine drives consist of various sources, including steam, water, gas, diesel engines, and others. The usefulness of a generator is as a source of electricity for the use of equipment or loads such as water pumps, oil pumps, lighting, and others.

A synchronous generator is an electric generator that converts mechanical energy as input into electrical energy as output energy. The output voltage of a synchronous generator is an alternating voltage, therefore a synchronous generator is also called an AC generator.

According to Anderson (1982) [6], synchronous generators can produce energy sources, namely alternating voltage, therefore synchronous generators are also called AC generators. It is said to be a synchronous generator because the number of rotations of the rotor is equal to the number of rotations of the magnetic field on the stator. This synchronous speed results from the rotational speed of the rotor with the magnetic poles rotating at the same speed as the rotating field on the stator [7].

If the rotor coil, which functions as a magnetic field generator located between the north and south magnetic poles, is rotated by water power or other power, then a magnetic field or rotating flux will arise. This rotary flux will cut the stator coil so that at the ends of the stator coil arises an electromotive force due to the induction effect of the rotary flux. The electromotive force (emf) arising on the stator coil is also alternating or rotating at a speed synchronous to the rotational speed of the rotor [8].

Sator coil induction emf or armature induction emf for each phase are [2]:

$$
E_{a}=4.44 f \frac{Z}{2} \varnothing K_{d}
$$

where,

$\mathrm{Ea}=$ Armature electromotive force every phase (Volt)

$\mathrm{f}=$ Generator output frequency $(\mathrm{Hz})$

$M=$ Number of coils per phase $=Z / 2$

$\mathrm{Z}=$ Number of conductors in all slots per phase

$\mathrm{K}_{\mathrm{d}}=$ Distribution factor.

$\Phi=$ magnetic flux at each pole of each phase

Figure 2 shows that in a synchronous generator, the anchor coil is also called a stator coil because it is in a fixed place, while the rotor coil together with the magnetic pole is rotated by mechanical power. According to Kundur (1993) [2], synchronous generator construction consists of two main parts, namely: the stator and the rotor. The stator is the stationary part that emits alternating voltage and the rotor is a moving part that produces a magnetic field that induces it to the stator.

In synchronous generators, a DC current is applied to the rotor windings to produce a rotor magnetic field. The rotor generator rotated by prime movers generates a rotating magnetic field on the engine. This rotating magnetic field induces a threephase voltage on the generator stator coil. The rotor in a synchronous generator is a large electromagnet. The rotor's magnetic field poles can be salient (shoe poles) and non-salient (cylindrical rotors). Figure 3 shows the shape of the shoe pole rotor.

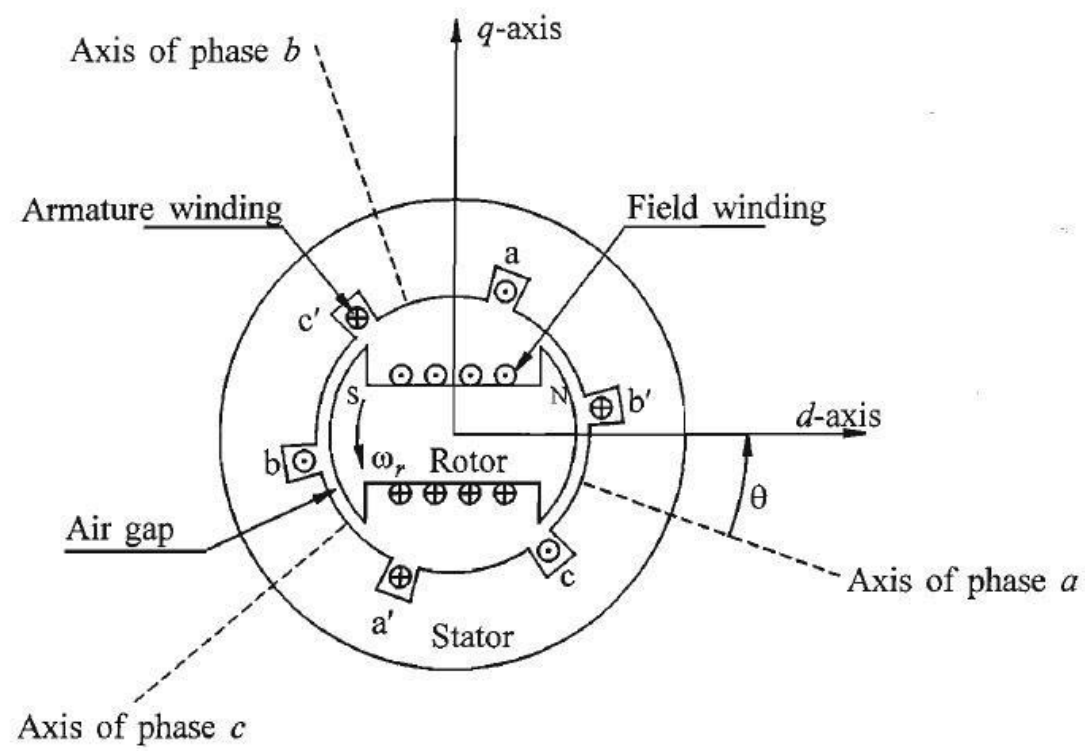

Figure 2. Three phase synchronous generator scheme 


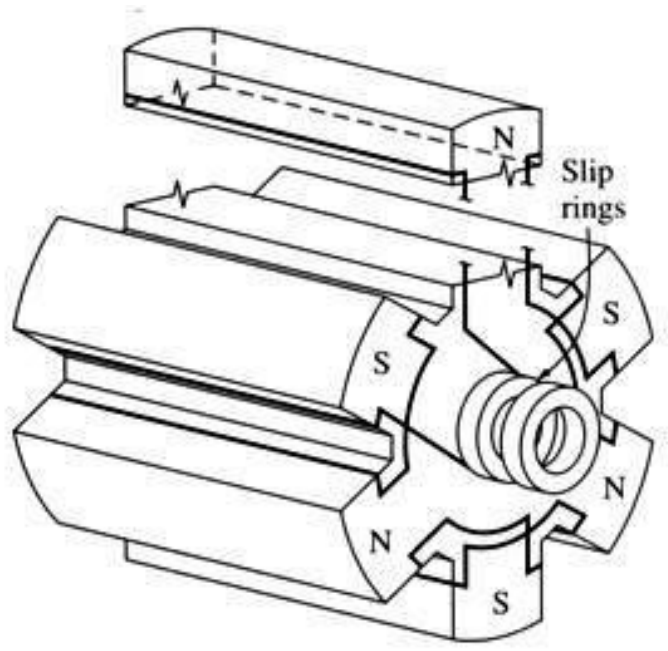

Fig. 3. Shape of the shoe pole rotor

Cylindrical rotors are generally used for twopole and four-pole rotors, while shoe-pole rotors are used for rotors with four or more poles. The choice of rotor construction depends on the primary rotational speed of the movers, the frequency and the power rating of the generator. Generators with speeds of $1500 \mathrm{rpm}$ and above at a frequency of 50 $\mathrm{Hz}$ and a power rating of around 10MVA using a cylindrical rotor. Meanwhile, for power below 10 MVA and low speed, shoe pole rotors are used. Figure 3 shows the shape of a cylindrical rotor.

Stator or armature is a generator that functions as a place to receive magnetic induction from the rotor. AC current to the load is channeled through the armature, this component is in the form of a cylindrical frame with a large number of conductor windings. Armature is always silent, therefore this component is also called a stator. The generator armature windings in wye and neutral points are connected to the ground [9].

The winding in wye was chosen because:

1. Increase output power.

2. Avoid harmonic voltages, so that the line voltage remains sinusoidal under any load conditions.

In wye winding the three harmonic voltages cancel each other out, while in harmonic voltage delta windings are added. The stator is a stationary part that emits alternating voltage on a synchronous generator consisting of: the stator frame, the stator core and stator grooves and teeth, and the stator coil. The stator frame is a house (frame) that supports the generator anchor core. The stator core is made of special alloy steel or special magnetic steel laminates attached to the stator frame. Chains and stator teeth

is a place to put the stator coil. There are three forms of stator grooves namely open, half open and closed. The three shapes of the grooves look like in Figure 4. Anchor coils are usually made of copper. This coil is a place where induction emf occurs [10].

The basic principle of alternating current generator uses Faraday's law which states that if a conductor is in a changing magnetic field, then the conductor will produce an electric motion. The working principle of a three-phase alternating current generator is the same as a single-phase alternating current generator, but in a three-phase generator, it has the same three windings and three different output voltages of 120 degrees at each phase $[11,12]$. If there is a change in the magnetic field around the conductor, then the conductor will generate an electromotive force (emf) which is opposed to the change in the field. To be able to create electromotive force (emf), two input categories are needed, namely:

1. Enter the mechanical power that will be generated by the prime mover.

2. Input current (If) in the form of direct current that will produce a magnetic field that can be easily adjusted.

If the generator rotor is rotated at its nominal speed, which is the rotation is obtained from the prime mover (prime mover), then the rotor field coil is given a field current of If, then the flux lines produced through the core poles will produce an induced voltage on the stator anchor coil of:

$$
\mathrm{Ea}=\text { C. n. } \Phi
$$

where:

Ea: Induced voltage generated at the generator anchor

C : Constants

$\mathrm{n}$ : Rotating speed

$\Phi$ : Flux generated by the amplifier current (field current).

\section{Methodology}

This research uses materials in the form of data related to power in turbines and generators as well as problems that cause turbines and generators that often disrupt the steam power plant of PT POMI Paiton. The location of this research is on Jalan Surabaya - Situbondo km 141, Binor, Paiton, Probolinggo, East Java, Indonesia. Figure 4 shows the location of the steam power plant at PT POMI Paiton.

In this study requires tools and materials in the 
form of hardware and software, namely the hardware used in this study is a unit of Asus core i7 laptop, and the software used in this research is Microsoft Word 2016 and Microsoft Excel 2016. The research steps of this study was shown in Figure 5.

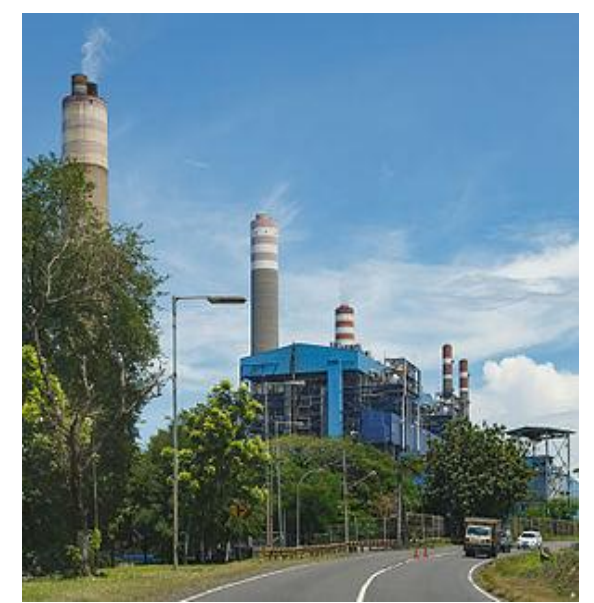

Fig. 4. Steam power plant at PT POMI Paiton

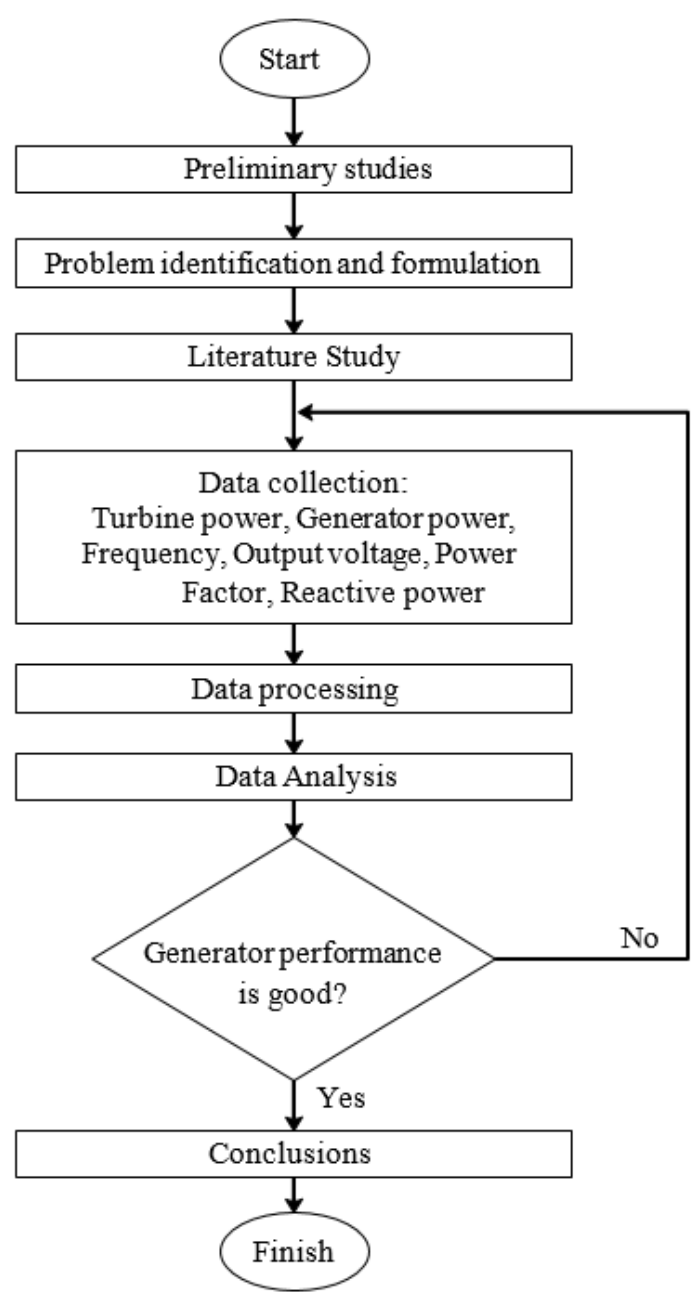

Fig. 5. The research steps of this study

\section{Results and Discussion}

\section{IV.1 Synchronous Generators at PT POMI Unit 7 Steam Power Plants}

In the PT POMI unit 7 steam power plant, it uses a synchronous generator. The generator is said to be synchronous if the phase sequence must be the same, the voltage must be the same, the frequency must be the same, and the phase angle must be the same. The working principle of a synchronous generator is based on electromagnetic induction. When the prime mover is coupled to the rotor, the prime mover operates then the rotor will rotate at a speed corresponding to the number of turns expected. If direct voltage (DC) supplies the polar coils, a magnetic field (magnetic force lines) arises on the polar surface that rotates at the same speed as the poles. The lines of the rotating magnetic force will cut the anchor coil contained in the stator so that the electromotive force (emf) coil arises. The emf generated at the anchor conductor is $\mathrm{AC}$ voltage.

\section{IV.2 Characteristics of Turbines and Generators in PT POMI Unit 7 Steam Power Plants}

At the PT POMI unit 7, the steam power plant has a total capacity of $615 \mathrm{MW}$, including turbines and generators. In turbines, there are three types of turbines, namely High-Pressure Turbines. Intermediate Turbine Pressure and Low-Pressure Turbine. And the power in this turbine is to determine the efficiency of the generator's performance. The generator used is a synchronous generator, which is said to be asynchronous if the phase sequence must be the same, the voltage must be the same, the frequency must be the same, and the phase angle must be the same. Table 1 shows the characteristics of the turbine while Teble 2 shows the characteristics of the generator.

TABLE I

CHARACTERISTICS OF THE TURBINE

\begin{tabular}{lc}
\hline \hline \multicolumn{1}{c}{ Manufacture } & General Electric \\
\hline Type & $280 \mathrm{~T} 330$ \\
Rated Output & $670 \mathrm{KW}$ \\
Pressure & $2400 \mathrm{PSIG}$ \\
Temperature & $1000^{\circ} \mathrm{F}$ \\
Reheat Temperature & $1000^{\circ} \mathrm{F}$ \\
Exhaust Pressure & $2.18 \mathrm{HGA}$ \\
\hline \hline
\end{tabular}


TABLE II

CHARACTERISTICS OF THE GENERATOR

\begin{tabular}{ll}
\hline \hline Rated Output & $846,231 \mathrm{KVA}$ \\
Armature Voltage & $23 \mathrm{Kv}$ \\
Armature Current & $21,242 \mathrm{~A}$ \\
Power Factor & 0.85 \\
Phase & 3 \\
Frequency & $50 \mathrm{~Hz}$ \\
Rotation speed & $3000 \mathrm{RPM}$ \\
Excitation voltage & $683 \mathrm{Volt}$ \\
Gas Pressure & $75 \mathrm{PSIG}$ \\
Connection & $2-\mathrm{Y}$ \\
Field Ampere & $4,670 \mathrm{~A}$ \\
\hline \hline
\end{tabular}

To determine the performance of the 280T330 generator in the PT POMI Paiton unit 7 steam power plant, there are several parameters such as generator output, power factor, efficiency, the relationship between active power, reactive power, and power factor and excitation system and power supply voltage. The performance of the generator determines the performance of the generator from 1 to 30 September 2018, as shown in Figure 5 until Figure 10.

To analyze the performance of 280T330 generator PT POMI Paiton steam power plant unit 7 with the generator output power output using the unit 7 daily operating power output data. Daily operating data to be analyzed for 30 days, starting from 1 to 30 September 2018. The following are power output generator unit 7 for 30 days.

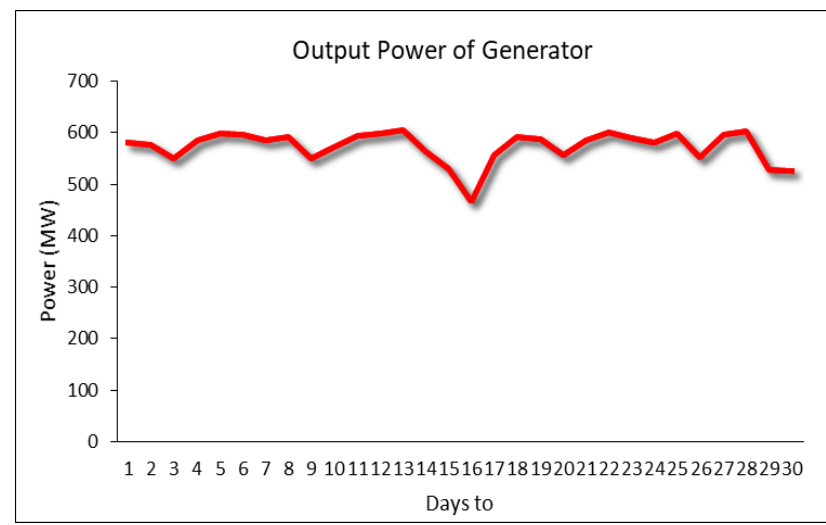

Fig. 6. The output power of generator in steam power plant at PT POMI Paiton

The output power of generator in steam power plant at PT POMI Paiton was shown in Figure 6. In the figure, it can be seen that the largest generator output power is 604.85 MW which occurred on September 13, 2018. This large power is caused when the load served by the generator is relatively high, thus requiring the generator to produce large power. Furthermore, the lowest power generated by the generator at the time of the investigation was on
September 16, 2018, which was 465.74 MW. This relatively small power is due to the need for electric power at relatively little load at that time.

The voltage power of generator in steam power plant at PT POMI Paiton was shown in Figure 7. In the figure it can be seen that the highest generator output voltage is $21.6299 \mathrm{kV}$ which occurred on September 1, 2018. This high voltage is caused when the load served by the generator is relatively not large, thus requiring the generator to produce a good voltage. Furthermore, the lowest output voltage generated by the generator at the time of the investigation was September 22, 2018, which was $21.3461 \mathrm{kV}$. This relatively low voltage is due to the need for electric power at very high loads at that time. A large load of power that causes this output voltage to drop must be anticipated to avoid a very low-frequency generator. Usually in this condition voltage control is done by adding fuel intake to the steam power plant. The addition of this fuel will be able to produce enough steam to turn the turbine so that a higher spin. This high turbine rotation is expected to produce a generator rotation that matches its rating.

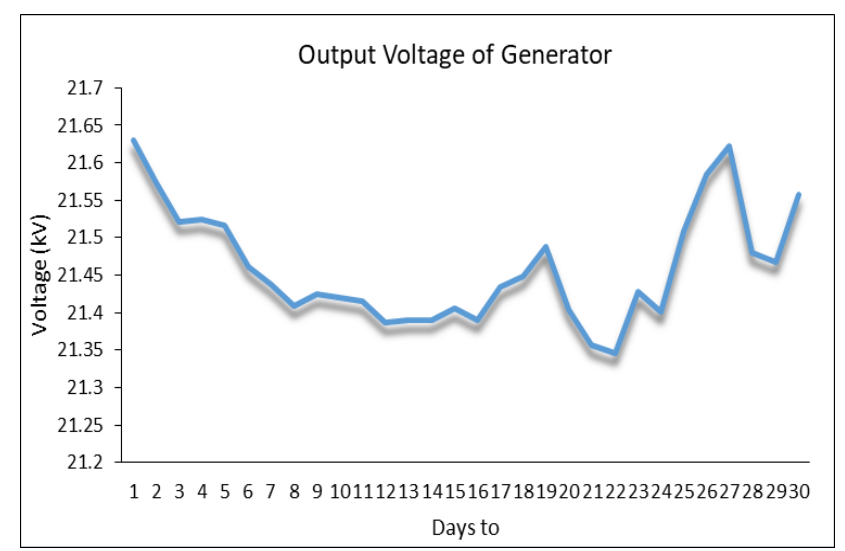

Fig. 7. The output voltage of generator in steam power plant at PT POMI Paiton

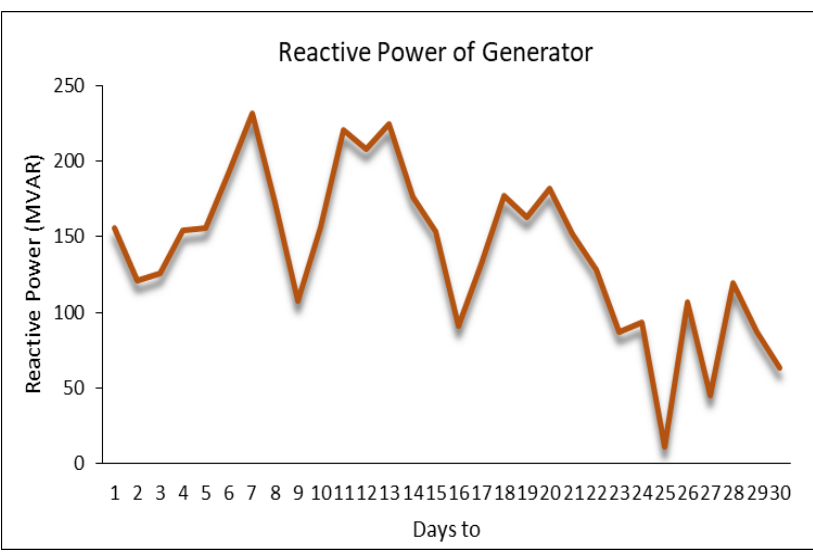

Fig. 8. The reactive power of generator in steam power plant at PT POMI Paiton 
The reactive power of generator in steam power plant at PT POMI Paiton was shown in Figure 8. In the figure, it can be seen that the largest generator output power is 231.7503 MVAR which occurred on September 7, 2018. This large reactive power is caused when the load served by the generator is relatively high, thus requiring the generator to produce large power. Furthermore, the lowest power generated by the generator at the time of the investigation was on September 25, 2018, which was 11.2169 MVAR. This relatively small reactive power is due to the need for electric power at relatively little load at that time.

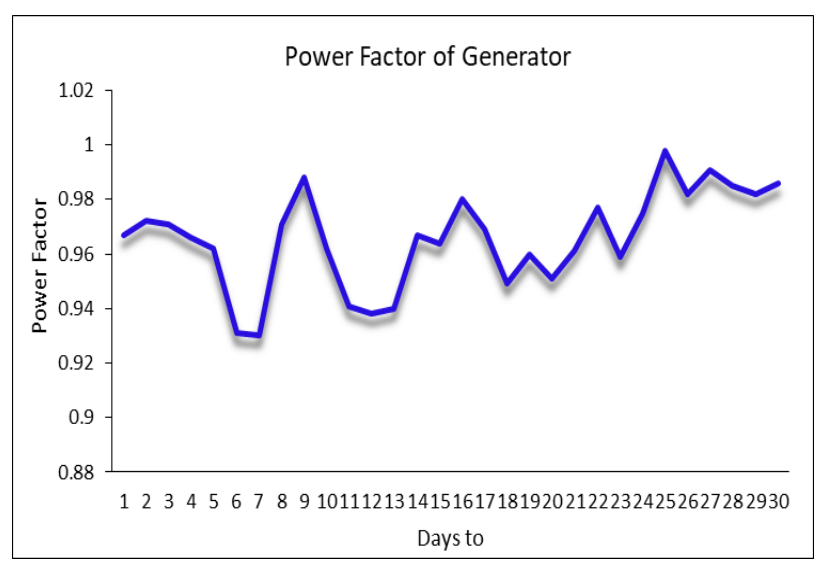

Fig. 9. The power factor of generator in steam power plant at PT POMI Paiton

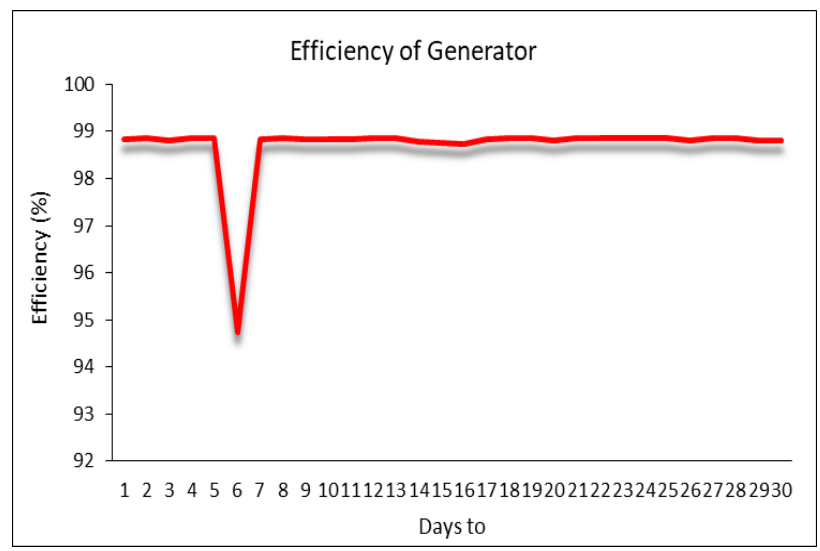

Fig. 10. The efficiency of generator in steam power plant at PT POMI Paiton

Figure 9 shows the power factor of generator in steam power plant at PT POMI Paiton. The figure shows that the highest generator power factor is 0.998 which occurred on September 25, 2018, while the lowest generator power factor was 0.930 which occurred on September 7, 2018. The active power is real power or power that is fed to the load. The size of the active power is influenced by voltage, and current, the higher the current and voltage, the active power will be even more significant and vice versa if the smaller the current and voltage, the active power will also be smaller.

From the data in Figure 6 and Figure 9, it can be observed that the power factor is influenced by active power and apparent power. The higher the active power and the smaller the apparent power, the more significant the power factor so that it approaches the value of 1 and vice versa if the smaller the active power and the higher the apparent power, the smaller the power factor.

Figure 10 shows the efficiency of the steam power plant at the PT POMI unit 7. The lowest efficiency occurred on September 7, 2018, namely $94.73 \%$. The lowest efficiency is due to the high apparent power generated by the generator at that time. Based on the data in Figure 10, it can be observed that the efficiency data conducted on 1 to 30 September 2018, still meet the design with a tolerance of \pm 5 . The efficiency of generators is affected by losses. The higher the losses, the smaller the efficiency and vice versa, the smaller the losses, the higher the efficiency.

\section{Conclusion}

The performance of the generator can be determined by investigating changes in active power, output voltage, reactive power, apparent power, power factor, frequency, and efficiency. Based on the results of research during September 2018, the output of the generator that determines the performance of the generator is the largest active power that occurred on September 13, 2018, namely 604.85 MW and the smallest active power occurred in September 16, 2018, which was 465.74 MW. The largest output voltage occurred on September 1, 2018, namely $21.6299 \mathrm{KV}$ and the lowest occurred on September 22, 2018, namely $21.3461 \mathrm{KV}$. Furthermore, the greatest reactive power occurred on September 7, 2018, which was 231.7503 MVAR and the lowest occurred on September 25, 2018, which was 11.2169 MVAR. The biggest power factor occurred on September 25, 2018, amounting to 0.998 and the lowest was on September 7, 2018, namely 0.9298 . The last parameter observed is the generator efficiency. The efficiency of the generator still fulfills the tolerance requirement of \pm 5 , where the highest load value occurs on September 13, 2018, which is 604.85 MW with the percentage of supply voltage of $-7.002 \%$ and the lowest load value occurs on September 16, 2018, which is 465.74 MW with percentage of supply voltage of 7,001\%. In general, generators at the PT Paiton Steam Power Plant which often happen only 
generator losses and not so disputed while not too large losses.

\section{References}

[1] Cahyadi. (2014). PLTU Batubara Superkritikal Yang Efisien. BALAI BESAR TEKNOLOGI ENERGI, BPPT Press, Jakarta.

[2] P. Kundur, Power System Stability and Control, Toronto, ON, Canada:McGraw-Hill, 1993.

[3] P. Krause, O. Wasynczuk, S. Sudhoff, S. Pekarek, Analysis of Electric Machinery and Drive Systems, Hoboken, NJ, USA:Wiley, 2013.

[4] IEEE. (2014). PC50.13/D2, Oct 2013 - IEEE Draft Standard for Cylindrical-Rotor $50 \mathrm{~Hz}$ and $60 \mathrm{~Hz}$ Synchronous Generators Rated 10 MVA and Above, ISBN: 978-0-7381-8902-4.

[5] IEEE. (2014). IEEE Standard for Cylindrical-Rotor $50 \mathrm{~Hz}$ and $60 \mathrm{~Hz}$ Synchronous Generators Rated 10 MVA and Above, IEEE Std C50.13-2014 (Revision of IEEE Std C50.13-2005).

[6] I. Tamrakar, L. B. Shilpakar, B. G. Fernandes, R. Nilsen, "Voltage and frequency control of parallel operated synchronous generator and induction generator with STATCOM in micro hydro scheme", IET Gener. Transmiss. Distrib., vol. 1, no. 5, pp. 743-750, Sep. 2007.

[7] B. Singh, S. S. Murthy, S. Gupta, "Analysis and design of STATCOM-based voltage regulator for self-excited induction generators", IEEE Trans. Energy Convers., vol. 19, no. 4, pp. 783-790, Dec. 2004.

[8] S. P. Gawande, K. B. Porate, K. L. Thakre, G. L. Bodhe, "Synchronization of synchronous generator and induction generator for voltage \& frequency stability using STATCOM", Proc. 3rd Int. Conf. Emerg. Trends Eng. Technol. (ICETET), pp. 407412, Nov. 2010.

[9] B. Singh, S. S. Murthy, R. S. Reddy, P. Arora, "Implementation of modified current synchronous detection method for voltage control of self-excited induction generator", IET Power Electron., vol. 8, no. 7, pp. 1146-1155, Jul. 2015.

[10] G. Pingping, L. Ziguang, L. Zhuo, W. Di, "PI-PSO algorithm based voltage controller of STATCOM for self-excited induction generator", Proc. 34th Chin. Control Conf. (CCC), pp. 4349-4354, Jul. 2015.

[11] A. Sarigiannidis, A. Kladas, E. Chatzinikolaou, C. Patsios, "High efficiency shaft generator drive system design for Ro-Ro trailer-passenger ship application", Proc. Int. Conf. Elect. Syst. Aircraft Railway Ship Propuls. Road Vehicles (ESARS), pp. 1-6, Mar. 2015.

[12] W. E. Vanço, F. B. Silva, J. R. B. A. Monteiro, J. M. M. de Oliveira, A. C. B. Alves, C. A. B. Júnior, "Analysis of the oscillations caused by harmonic pollution in isolated synchronous generators", Electr. Power Syst. Res., vol. 147, pp. 280-287, Jun. 2017.

\section{Authors' information}

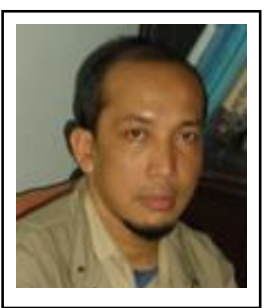

Ramadoni Syahputra received B.Sc. degree from Institut Teknologi Medan in 1998, M.Eng. degree from Department of Electrical Engineering, Universitas Gadjah Mada, Yogyakarta, Indonesia in 2002, and Ph.D. degree at the Department of Electrical Engineering, Faculty of Industrial Technology, Institut Teknologi Sepuluh Nopember, Surabaya, Indonesia in 2015.

Dr. Ramadoni Syahputra is a Lecturer in Department of Electrical Engineering, Faculty of Engineering, Universitas Muhammadiyah Yogyakarta, Indonesia. His research interests are in computational of power system, artificial intelligence in power system, power system control, the application of fuzzy logic in power system, optimization, distributed energy resources, and renewable energy.

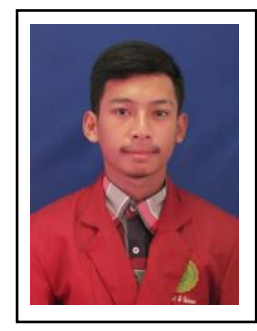

Andi Wahyu Nugroho received B.Sc. degree from Department of Electrical Engineering, Universitas Muhammadiyah Muhammadiyah Yogyakarta, Yogyakarta, Indonesia in 2018.

His research interests are in operation of power distribution system and power distribution system planning.

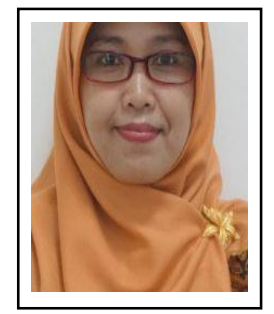

Anna Nur Nazilah Chamim obtained her B.Eng. in Electrical Engineering from Universitas Muhammadiyah Yogyakarta, Indonesia. Her Master study was done at 2015 at the Electrical Engineering, Universitas Gadjah Mada, Indonesia. She currently is a lecture in department of Electrical engineering, Universitas Muhammadiyah Yogyakarta. Her main research interest is in electronics, telecommunication, and signal processing.

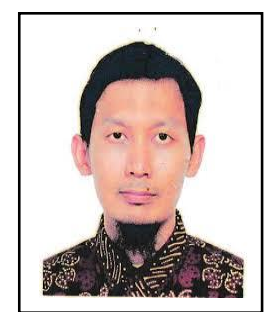

Widyasmoro is a lecturer and researcher in Electrical Engineering Department, Faculty of Engineering, Universitas Muhammadiyah Yogyakarta (UMY).

He received bachelor degree from Department of Electrical Engineering of Universitas Jenderal Sudirman, Indonesia, and M.Eng. degree from Department of Electrical Engineering of Asia University, Taiwan. His research interests are in electronics, telecommunication, and control system.

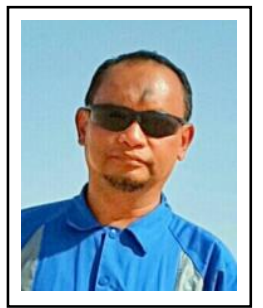

Teguh Iman Prasetyo hold a bachelor degree in 2000 from Electrical Engineering Department, Universitas Muhammadiyah Yogyakarta, Indonesia. Mr. Teguh Iman Prasetyo is currently a professional in Production on the Job Trainer and Competence Assessor, Petroleum Development Oman, Muscat, Sultanate of Oman. His main research interest is in control system and distributed control system. 